\title{
Improving detection of "Viridans streptococcus" bacteraemia by adding sodium polyanethol sulphonate to blood cultures
}

\author{
DC SHANSON, FD THOMAS, * D JOHNSTONE \\ From the Departments of Clinical Microbiology and *Oral Surgery, St Stephen's Hospital, London
}

SUMMARY To detect streptococcal bacteraemia in patients undergoing dental extraction blood cultures containing glucose broth with $0.05 \%$ sodium polyanethol sulphonate (Liquoid) were compared with identical cultures without Liquoid.

Optimal techniques for blood culture are important for the reliable detection of low grade bacteraemia caused by Viridans streptococcus and are especially relevant for the microbiological diagnosis of infective endocarditis. Previous in vitro studies suggested that the inclusion of $0.05 \%$ sodium polyanethol sulphonate (Liquoid) in blood culture broths would increase the recovery of streptococcus by neutralising the antibacterial effects of fresh human blood ${ }^{1}$ and that at least a 1/30 dilution of blood in broth would be required for the optimal recovery of streptococci in broths without Liquoid. ${ }^{2}$ It has also been suggested that occasional strains of Viridans streptococcus may be inhibited by $0.05 \%$ Liquoid. $^{3}$ A survey in Britain showed that about half of all laboratories included Liquoid in blood culture broths for isolating aerobes. ${ }^{4}$ Many laboratories in Britain use $50 \mathrm{ml}$ glucose broth for the culture of $5 \mathrm{ml}$ blood samples, and it is sometimes assumed in practice that a $1 / 10$ dilution of blood in broth will inactivate the antibacterial effect of fresh blood. We decided to compare these glucose broths with and without $0.05 \%$ Liquoid for the recovery of Viridans streptococcus from the blood of patients undergoing dental extraction.

\section{Material and methods}

Patients requiring dental extraction under general anaesthesia who had not received recent antibiotics were included in the study. Most patients did not have obvious dental sepsis at the time of extraction. Blood was collected for culture about one and a half minutes after extraction of the first tooth.

Accepted for publication 10 July 1985
MEDIA AND LIQUOID

Blood culture bottles were supplied by Southern Group Laboratories, (Hither Green, London) containing $50 \mathrm{ml}$ digest broth with $0.1 \%$ glucose. Identical broths with and without about $0.05 \%$ Liquoid were supplied ready for use.

BROTH CULTURE METHOD

Immediately after $30 \mathrm{ml}$ blood had been collecteg from each patient $5 \mathrm{ml}$ was added to each of six blood culture broths. Alternate inoculation of broths with and without Liquoid was carried out, so that each type of broth was tested in triplicate. Broths were incubated at $35^{\circ} \mathrm{C}$ and subcultured after $1,3,5$, and 10 days on to blood agar. The blood agar plates were also inoculated with a Staphylococcus aureus streak to assist with the isolation of any pyridoxal dependent satellite streptococcus. The subculture plates were incubated aerobically for $\mathbf{4 8}$ hours in a carbon dioxide incubator.

IDENTIFICATION OF STREPTOCOCCI Alpha or non-haemolytic Gram positive cocci on blood agar that grew aerobically and were coagulase negative, catalase negative, and optochin resistant were presumptively identified as Viridans streptococcus. These were further identified by the API 20 streptococcal identification test (API Laboratory Products, Basingstoke, Hampshire).

\section{Results}

Bacteraemia with Viridans streptococcus was detected in 20 of the 59 patients. Significantly more cases of $\stackrel{\mathcal{Q}}{?}$ bacteraemia were detected by the blood culture broths with $0.05 \%$ Liquoid on each day of subculture (Table, $\mathrm{p}<0.003)$. The results after 10 days of incubation 1346 
Table 1 Results of culture of blood broths with and without Liquoid for detecting bacteraemia caused by viridans type streptococci (figures are numbers of broths yielding the organism)

\begin{tabular}{|c|c|c|c|c|c|c|c|c|}
\hline \multirow{2}{*}{$\begin{array}{l}\text { Case } \\
\text { no }\end{array}$} & \multicolumn{2}{|l|}{ Day 1} & \multicolumn{2}{|l|}{ Day 3} & \multicolumn{2}{|l|}{ Day 5} & \multirow{2}{*}{$\begin{array}{l}\text { Final } \\
\text { total }^{*}\end{array}$} & \multirow{2}{*}{$\begin{array}{l}\text { Identity of } \\
\text { organism }\end{array}$} \\
\hline & Liquoid & Non-liquoid & Liquoid & Non-liquoid & Liquoid & Non-liquoid & & \\
\hline $\begin{array}{l}1 \\
2 \\
3 \\
4 \\
5 \\
6 \\
7 \\
8 \\
9 \\
10 \\
11 \\
12 \\
13 \\
14 \\
15 \\
16 \\
17 \\
18 \\
19 \\
20 \\
21-59 \\
\text { Total No of broths positive } \\
\text { Total No of broths tested } \\
\text { No of patients in whom } S \text { v }\end{array}$ & $\begin{array}{c}1 \\
1 \\
\\
3 \\
2 \\
1 \\
1 \\
2 \\
2 \\
2 \\
3 \\
3 \\
1 \\
2 \\
2 \\
2 \\
\\
\text { e } 28 \\
177 \\
\text { viridans a } \\
15\end{array}$ & $\begin{array}{l}2 \\
1 \\
1 \\
2 \\
1 \\
2\end{array}$ & $\begin{array}{l}1 \\
1 \\
1 \\
2 \\
3 \\
2 \\
1 \\
1 \\
2 \\
2 \\
2 \\
3 \\
3 \\
1 \\
3 \\
2 \\
2 \\
3\end{array}$ & $\begin{array}{l}2 \\
1 \\
1 \\
2 \\
2 \\
1 \\
3\end{array}$ & $\begin{array}{r}1 \\
1 \\
1 \\
1 \\
2 \\
3 \\
2 \\
1 \\
1 \\
2 \\
2 \\
2 \\
3 \\
3 \\
1 \\
3 \\
3 \\
2 \\
3 \\
2 \\
39 \\
177\end{array}$ & $\begin{array}{r}2 \\
1 \\
1 \\
2 \\
2 \\
1 \\
3 \\
1 \\
13 \\
177 \\
8\end{array}$ & $\begin{array}{l}1 \\
1 \\
1 \\
1 \\
2 \\
3 \\
2 \\
1 \\
1 \\
2 \\
2 \\
2 \\
5 \\
4 \\
2 \\
5 \\
5 \\
3 \\
6 \\
3\end{array}$ & $\begin{array}{l}S \text { mitior } \\
S \text { salivarius } \\
S \text { mutans } \\
S \text { milleri } \\
S \text { milleri } \\
S \text { milleri } \\
S \text { sanguis } \\
S \text { mitior } \\
S \text { mitior } \\
S \text { salivarius } \\
S \text { mitior } \\
S \text { mitior } \\
S \text { milleri } \\
S \text { mitior } \\
S \text { sanguis } \\
S \text { mitior } \\
S \text { sanguis } \\
S \text { sanguis } \\
S \text { mitior } \\
S \text { mitior }\end{array}$ \\
\hline
\end{tabular}

*Positive broths with and without Liquoid six tested for each patient).

were the same as those after five days of incubation. The final numbers of patients with streptococcal bacteraemia detected by the Liquoid and non-Liquoid culture broths were 20 and eight, respectively. The total number of broths positive for Viridans streptococcus in the blood cultures containing Liquoid compared with the cultures without Liquoid were 39 and 13, respectively. These differences in the results obtained between Liquoid and non-Liquoid blood cultures were highly significant (sign test, $\mathrm{p}<0.003$ ).

In 11 of the cases in which streptococcal bacteraemia was detected only by the broths containing Liquoid, only one or two of the three broths containing Liquoid were positive. In contrast, in each of the eight cases in which the bacteraemia was detected by both types of culture broths two to six broths were positive (out of the six inoculated).

\section{Discussion}

Our study is the first clinical comparison of media that has shown a significant advantage for the inclusion of $0.05 \%$ Liquoid in blood culture broths for detecting bacteraemia due to Viridans streptococcus. These results are important as the $1 / 10$ dilution of blood in broth and the glucose broth used in the study are often used for the microbiological diagnosis of infective endocarditis. A recent study of the effectiveness of different anaerobic broths for detecting streptococcal bacteraemia failed to show any advantage for the inclusion of $0.05 \%$ Liquoid in $75 \mathrm{ml}$ fastidious anaerobe broth, ${ }^{5}$ but in this study the dilution of the patient's blood in broth was $1 / 17$. The advantage of including $0.05 \%$ Liquoid in broth will probably be seen more often in blood culture systems in which blood is diluted up to only about $1 / 10$ than in cultures in which the dilution factor is equal to or greater than $1 / 17$.

The total number of positive broths was four on average, when streptococcal bacteraemia was detected by blood cultures both with and without Liquoid, but only one or two when the bacteraemia was detected solely by the broths that included Liquoid. This finding suggests that the main advantage of including Liquoid in broths can be expected when relatively few streptococci are present in the blood sample collected. No patient had streptococcal bacteraemia detected only by broths without Liquoid, and this indicates that inhibition of Viridans streptococcus by $0.05 \%$ Liquoid is not a major problem.

In conclusion, we recommend that $0.05 \%$ Liquoid be routinely included in blood culture broths, in which blood is diluted up to about $1 / 10$ for the optimal detection of bacteraemia caused by Viridans streptococcus. This is likely to be especially important for the reliable microbiological diagnosis of streptococcal endocarditis. 
We thank members of the anaesthetic department who assisted with the collection of blood cultures.

\section{References}

${ }^{1}$ Von Haebler T, Miles AA. The action of sodium polyanethol sulphonate ('Liquoid') on blood cultures. Journal of Pathology and Bacteriology 1938;46:245-52.

${ }^{2}$ Roome AP, Tozer RA. Effect of dilution on the growth of bacteria from blood cultures. J Clin Pathol 1968;21:719-21.

${ }^{3}$ Penfold JB, Goldman J, Fairbrother RW. Blood-cultures and selec- tion of media. Lancet $1940 ; \mathrm{i}: 65$.

${ }^{4}$ Shanson DC. Blood culture techniques. In: Williams JD, ed. Modern topics in infection. London: Heinemann, 1978:14-30.

${ }^{5}$ Shanson DC, Moule I, Tadayon M. Clinical comparison of anaerobic blood-culture media for detecting bacteraemia due to viridans streptococci and oral anaerobes. J Med Microbiol 1985;19:187-93.

Requests for reprints to: Dr DC Shanson, Department of Clinical Microbiology, St Stephen's Hospital, Chelsea, London SW10 9TH, England. 